Article

\title{
A Modified Bacillus Calmette-Guérin (BCG) Vaccine with Reduced Activity of Antioxidants and Glutamine Synthetase Exhibits Enhanced Protection of Mice despite Diminished in Vivo Persistence
}

Carolyn M. Shoen ${ }^{1}$, Michelle S. DeStefano ${ }^{1}$, Cynthia C. Hager ${ }^{2}$, Kyi-Toe Tham ${ }^{3,4, \dagger}$, Miriam Braunstein ${ }^{5}$, Alexandria D. Allen ${ }^{2, *}$, Hiriam O. Gates ${ }^{2}$, Michael H. Cynamon ${ }^{1}$ and Douglas S. Kernodle ${ }^{2,4,6, *}$

1 Veterans Affairs Medical Center, Syracuse, NY 13212, USA;

E-Mails: shoenc@cnyrc.org (C.M.S.); Michelle.Destefano@va.gov (M.S.D.);

Michael.Cynamon@va.gov (M.H.C.)

2 Department of Medicine, Vanderbilt University Medical Center, Nashville, TN 37232, USA;

E-Mails: cindy.hager@vanderbilt.edu (C.C.H.); Alexandria.Allen@mlh.org (A.D.A.);

hirham@bellsouth.net (H.O.G.)

3 Department of Pathology, Vanderbilt University Medical Center, Nashville, TN 37232, USA;

E-Mail: kyitoe@catham.org

4 Veterans Affairs Medical Center, Nashville, TN 37212, USA

5 Department of Microbiology and Immunology, University of North Carolina, Chapel Hill, NC 27599, USA; E-Mail: braunste@med.unc.edu

6 Department of Microbiology, Immunology and Pathology, Vanderbilt University Medical Center, Nashville, TN 37232, USA

$\dagger$ Present Address: Department of Pathology, University of Washington, Seattle, WA 98195, USA

$\$$ Present Address: Department of Medicine, University of Tennessee Health Science Center, Memphis, TN 38163, USA

* Author to whom correspondence should be addressed; E-Mail: doug.kernodle@vanderbilt.edu; Tel.: +1-615-936-3310; Fax: +1-615-343-6160.

Received: 26 October 2012; in revised form: 18 December 2012 / Accepted: 5 January 2013 / Published: 11 January 2013

Abstract: Early attempts to improve BCG have focused on increasing the expression of prominent antigens and adding recombinant toxins or cytokines to influence antigen 
presentation. One such modified BCG vaccine candidate has been withdrawn from human clinical trials due to adverse effects. BCG was derived from virulent Mycobacterium bovis and retains much of its capacity for suppressing host immune responses. Accordingly, we have used a different strategy for improving BCG based on reducing its immune suppressive capacity. We made four modifications to BCG Tice to produce $4 \mathrm{dBCG}$ and compared it to the parent vaccine in $\mathrm{C} 57 \mathrm{Bl} / 6$ mice. The modifications included elimination of the oxidative stress sigma factor SigH, elimination of the SecA2 secretion channel, and reductions in the activity of iron co-factored superoxide dismutase and glutamine synthetase. After IV inoculation of $4 \mathrm{dBCG}, 95 \%$ of vaccine bacilli were eradicated from the spleens of mice within 60 days whereas the titer of BCG Tice was not significantly reduced. Subcutaneous vaccination with $4 \mathrm{dBCG}$ produced greater protection than vaccination with BCG against dissemination of an aerosolized challenge of $M$. tuberculosis to the spleen at 8 weeks post-challenge. At this time, 4dBCG-vaccinated mice also exhibited altered lung histopathology compared to BCG-vaccinated mice and control mice with less well-developed lymphohistiocytic nodules in the lung parenchyma. At 26 weeks post-challenge, 4dBCG-vaccinated mice but not BCG-vaccinated mice had significantly fewer challenge bacilli in the lungs than control mice. In conclusion, despite reduced persistence in mice a modified BCG vaccine with diminished antioxidants and glutamine synthetase is superior to the parent vaccine in conferring protection against $M$. tuberculosis. The targeting of multiple immune suppressive factors produced by BCG is a promising strategy for simultaneously improving vaccine safety and effectiveness.

Keywords: tuberculosis; vaccine; Bacillus Calmette-Guérin (BCG); antioxidants; superoxide dismutase; sigma factor; glutamine synthetase; immunity; immune suppression

\section{Introduction}

Tuberculosis (TB) remains an enormous global health problem despite the vaccination of more than 100 million newborns annually with Bacillus Calmette-Guérin (BCG), the current live-attenuated vaccine against TB [1,2]. The high prevalence of HIV infection in some countries combined with the rising incidence of infection caused by extensively drug-resistant strains of Mycobacterium tuberculosis threaten to make a dire global TB situation even worse.

BCG has been used as a vaccine against TB for 9 decades. It was identified in 1921 as an attenuated mutant of $M$. bovis and was cultivated for decades in laboratories throughout the world. During this time it underwent divergent evolution and the currently-available BCG daughter strains (substrains) differ from each other and from the original BCG vaccine, which no longer exists $[3,4]$. BCG provides $80 \%$ protection against miliary and meningeal $\mathrm{TB}$ in childhood and the routine vaccination of newborns in much of the world is estimated to prevent about 40,000 cases annually [5,6]. In early studies, BCG was also highly efficacious against pulmonary TB with about $80 \%$ protection over the first 2 decades and up to 50\% protection was still evident 6 decades after vaccination [7-9]. However, the effectiveness of the BCG daughter strains against pulmonary TB appears to have declined over 
time for reasons that continue to be debated $[10,11]$. Pulmonary TB is much more common than the disseminated forms of TB and accounts for the vast majority of the TB global burden. Pulmonary TB is also the contagious form of TB and thus an effective vaccine against pulmonary TB should reduce all forms of TB.

In an effort to restore BCG's ability to protect against pulmonary TB, we have enhanced BCG's immunogenicity by reducing the activity and secretion of microbial antioxidants [12]. This approach differs markedly from the more common strategy of modifying BCG by increasing its production of prominent antigens and adding recombinant toxins or cytokines [13-15]. However our approach is well-founded in the context of reports that mycobacterial antioxidants suppress host immune responses and there is growing evidence that they also promote the pathogenesis of granulomatous inflammation [16-22]. Furthermore, it appears that as BCG was cultivated in vitro for decades it increased its production of antioxidants by a process involving duplication of regions of chromosomal DNA and other mutations [4], and this increase may partly explain the decline in its protective efficacy against pulmonary TB over time $[11,12]$. Thus, although we have not specifically undone the multiple mutations that arose in BCG during decades of in vitro cultivation, reducing the activity of microbial antioxidants makes our modified BCG more like the early BCG vaccine that was effective in preventing pulmonary TB.

In the present investigation we make four modifications to BCG including reducing the activity of glutamine synthetase (GlnA1), a secreted mycobacterial enzyme implicated in immune evasion [23-25], thereby producing 4dBCG with diminished antioxidant and GlnA1 activity. We then compare 4dBCG to $\mathrm{BCG}$ in vivo including an assessment of the persistence of vaccine strains in the spleens of mice. We also use a vaccination-challenge model to assess protection against hematogenous dissemination and lung pathology after aerosol inoculation of vaccinated mice with $M$. tuberculosis. We find that although $4 \mathrm{dBCG}$ is cleared more rapidly than BCG from the spleens of mice, it provides greater protection against dissemination of an aerosolized challenge with $M$. tuberculosis and also alters lung histopathology. The clinical implications of these findings are discussed in the context of the difficulties in correlating results in mice with results in man.

\section{Results and Discussion}

\subsection{Construction of $4 d B C G$}

Details of the construction of $3 \mathrm{dBCG}$, with three genetic modifications of the parent BCG Tice vaccine strain, have been previously reported [12]. Two of the modifications involved allelic inactivation of $\operatorname{sig} H$, the oxidative stress sigma factor [20,26,27] and $\sec A 2$, the secretion channel for iron co-factored superoxide dismutase (SodA) [17,18]. A third modification involved recombinant expression of a dominant-negative $\Delta \mathrm{H} 28 \Delta \mathrm{H} 76$ mutant of $\operatorname{sod} A$ that reduced SodA activity by more than $90 \%$ compared to the parent vaccine. GlnA1 is another microbial factor implicated in immune suppression that has been shown to confer resistance to killing of $M$. tuberculosis by human macrophages [24,25]. As GlnA1 is essential for the growth of M. tuberculosis [28] we partially lowered GlnA1 activity by using dominant-negative interference techniques while preserving potentially important epitopes for immune recognition [29]. First we deleted two amino acids that are 
important for enzymatic activity, an aspartic acid at position 50 and glutamic acid at position 327 (Figure 1A). Then we inserted the allele encoding the $\Delta \mathrm{D} 50 \Delta \mathrm{E} 327 \mathrm{GlnA} 1$ monomer on a plasmid vector into $3 \mathrm{dBCG}$ to yield $4 \mathrm{dBCG}$. Immunoblotting demonstrated that enzyme activity was reduced 8 -fold in $4 \mathrm{dBCG}$, verifying a dominant-negative effect (Figure 1B,C).

Figure 1. Construction of $4 \mathrm{dBCG}$. (A) Hexameric ring representing half of the enzymatically-active dodecameric form of GlnA1 (left) and enlargement (right) of the area within the rectangle to show the deleted amino acids in relationship to the active site manganese atom, represented by the black dot, with amino acids numbered according to the glutamine synthetase of Salmonella [30]. As the active site comprises residues from adjacent monomers, insertion of one $\triangle \mathrm{D} 50 \Delta \mathrm{E} 327 \mathrm{dnGlnA} 1$ monomer into the ring is predicted to inactivate two active sites. (B) SDS-PAGE (upper) and immunoblot (lower) for GlnA1 of lysates of Bacillus Calmette-Guérin (BCG), 3dBCG and 4dBCG. Lanes are labeled on the figures as L (lysate) and AS (ammonium sulfate-treated lysate) for each strain, $\mathrm{kDaM}=$ Kilodalton markers. $(\mathbf{C})$ Graph of a representative experiment comparing the glutamine synthetase activity of undiluted and diluted AS preparations from $3 \mathrm{dBCG}$ and $4 \mathrm{dBCG}$ as determined by monitoring $\mathrm{A}_{540}$ over time.

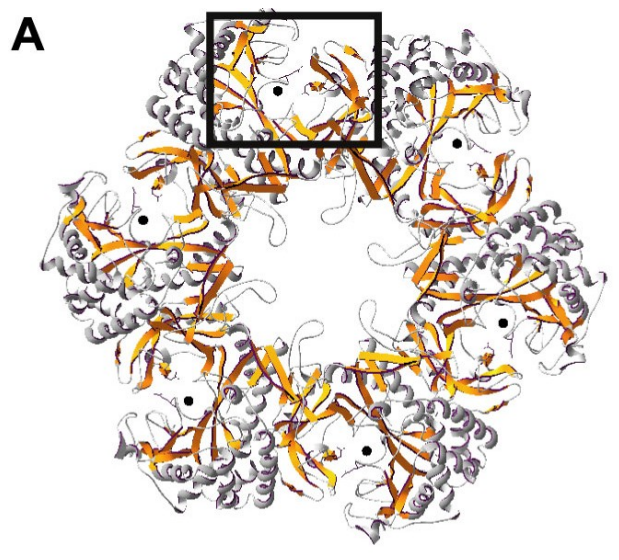

B

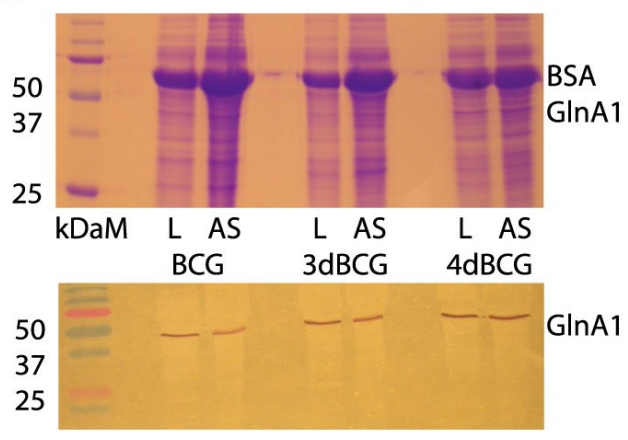

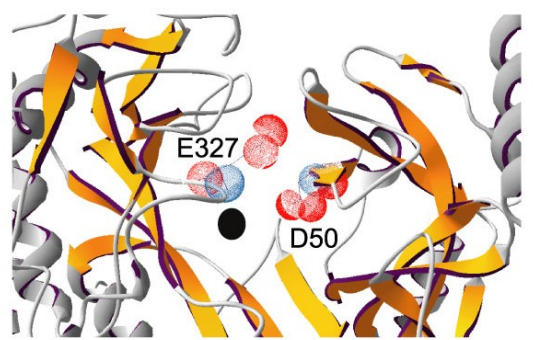

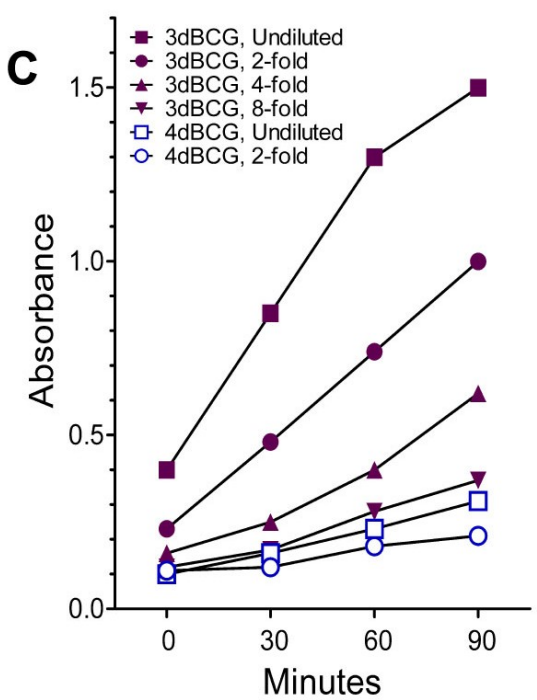

\subsection{4dBCG Is Cleared More Rapidly than BCG from the Spleens of Mice}

BCG daughter strains that exhibit relative invasiveness and persistence in animal models such as BCG Pasteur 1173P2 and BCG Danish 1331 cause more adverse effects in man than less virulent BCG substrains such as BCG Tokyo $172[1,31,32]$. In the context of the recent withdrawal of the recombinant BCG vaccine candidate Aeras-422 from human clinical trials due to adverse effects $[33,34]$, 
assessment of the virulence of the live vaccine strains has become an increasingly important part of the initial evaluation of a live vaccine candidate.

To determine whether or not our modifications altered the in vivo persistence of vaccine bacilli, we administered $2 \times 10^{7} \mathrm{cfu}$ of $\mathrm{BCG}$ or $4 \mathrm{dBCG}$ intravenously to $\mathrm{C} 57 \mathrm{Bl} / 6$ mice. At day 60 post-inoculation the mean titer of BCG was lower, albeit not significantly, than the mean titer at day 2 post-inoculation $p=0.07$, Figure 2). In contrast, the number of $4 \mathrm{dBCG}$ bacilli fell by more than $95 \%$ over the same period of time $(p=0.01)$ and was 20 -fold less than the titer of BCG at day 60 post-inoculation ( $p=0.002$ ). In summary, $4 \mathrm{dBCG}$ did not persist as well as the parent BCG vaccine in the spleens of mice. The reduced persistence of $4 \mathrm{dBCG}$ may partly reflect a slower intrinsic growth rate combined with greater unmasking and activation of innate and adaptive host responses that mediate the clearance of live mycobacteria from host organs.

Figure 2. Spleen titers of $\mathrm{BCG}$ and $4 \mathrm{dBCG}$ in $\mathrm{C} 57 \mathrm{Bl} / 6$ mice. Mean $\pm \mathrm{SEM}$ spleen titers on day 2, day 30, and day 60 after IV inoculation of mice with $2 \times 10^{7} \mathrm{cfu}$ of BCG or $4 \mathrm{dBCG}$. Each value represents four to six mice. The $\mathrm{P}$ value represents the comparison of the BCG and $4 \mathrm{dBCG}$ groups at 60 days. The day 0 value is estimated as $10 \%$ of the original IV inoculum.

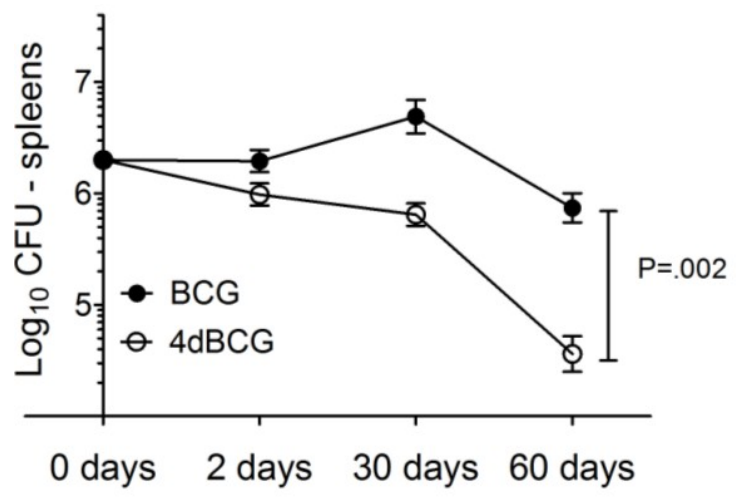

\subsection{Vaccination with $4 d B C G$ Exhibits Greater Protection than BCG against Early Dissemination of} Aerosolized M. tuberculosis to the Spleen

For nearly 6 decades it has been appreciated that BCG substrains differ in their ability to interfere with the hematogenous dissemination of a challenge dose of M. tuberculosis in animal models [35]. Furthermore, relatively virulent BCG substrains capable of persisting in relatively high titer in the organs of mice protect best in small animal models and thus have been considered by some authorities to have greater vaccine potency [35-41]. Accordingly, we wondered whether our modifications to $\mathrm{BCG}$ that reduced the in vivo persistence of $4 \mathrm{dBCG}$ would also reduce the ability of $4 \mathrm{dBCG}$ to protect against hematogenous dissemination.

We compared mice vaccinated with $\mathrm{BCG}$ or $4 \mathrm{dBCG}$ to control mice that were vaccinated with phosphate-buffered saline (PBS), using 15 mice per vaccination arm. At 8 weeks after subcutaneous vaccination with $2 \times 10^{7} \mathrm{cfu}$ of the vaccine strains, mice were challenged by aerosol with $100 \mathrm{cfu}$ of M. tuberculosis strain Erdman S-1. To assess hematogenous dissemination, we determined spleen cfu counts at 8 weeks post-aerosol challenge. At this time, PBS-vaccinated mice harbored a median of 
$1.8 \times 10^{5}$ bacilli in the spleen. CFU titers were 5.8-fold lower in BCG-vaccinated mice (median, $3.1 \times 10^{4} \mathrm{cfu}$ ) and 18-fold lower in 4dBCG-vaccinated mice (median, $1.0 \times 10^{4} \mathrm{cfu}$, Figure 3).

Lung cfu titers were also determined. PBS-vaccinated mice exhibited a median of $9.7 \times 10^{4} \mathrm{cfu}$ at 8 weeks post-challenge and titers were 3.6-fold lower in BCG-vaccinated mice (median, $2.7 \times 10^{4} \mathrm{cfu}$ ) and 7.5-fold lower in 4dBCG-vaccinated mice (median, $1.3 \times 10^{4} \mathrm{cfu}$ ). These results paralleled the findings in the spleen and represent the growth over time of the original aerosolized inoculums of bacteria within the lung combined with bronchogenic and hematogenous dissemination to other parts of the lung. Results at 26 weeks are described below (Section 2.5)

Figure 3. Titer of $M$. tuberculosis challenge bacilli in the spleens and left lungs of $\mathrm{C} 57 \mathrm{~B} 1 / 6$ mice. Mice received aerosol challenge with $100 \mathrm{cfu}$ of M. tuberculosis strain Erdman S-1. The whole spleens and left lungs were assessed for cfu titer while the right lungs were processed for histopathology as shown in Figures 4-7. The individual data points (circles) and median (bar) for each vaccination arm are shown at 8 weeks (top, six mice per vaccination arm) and 26 weeks (bottom, eight or nine mice per vaccination arm) post-challenge. The dotted lines extend the bar representing the median value of the PBS-vaccinated and BCG-vaccinated groups and are marked $\mathrm{P}^{*}$ and $\mathrm{P}^{* *}$, respectively. Analysis of spleen and lung results at 8 weeks and lung results at 26 weeks by 1 way ANOVA demonstrated that the median values of the groups varied significantly by Kruskal-Wallis test. The groups were also compared using the Mann-Whitney test and values in the row labeled $\mathrm{P}^{*}$ above the panel indicate the comparison of each vaccinated group against the phosphate-buffered saline (PBS) group. The values in the row labeled $\mathrm{P}^{* *}$ indicate the comparison of the $4 \mathrm{dBCG}$ and $\mathrm{BCG}$ groups.
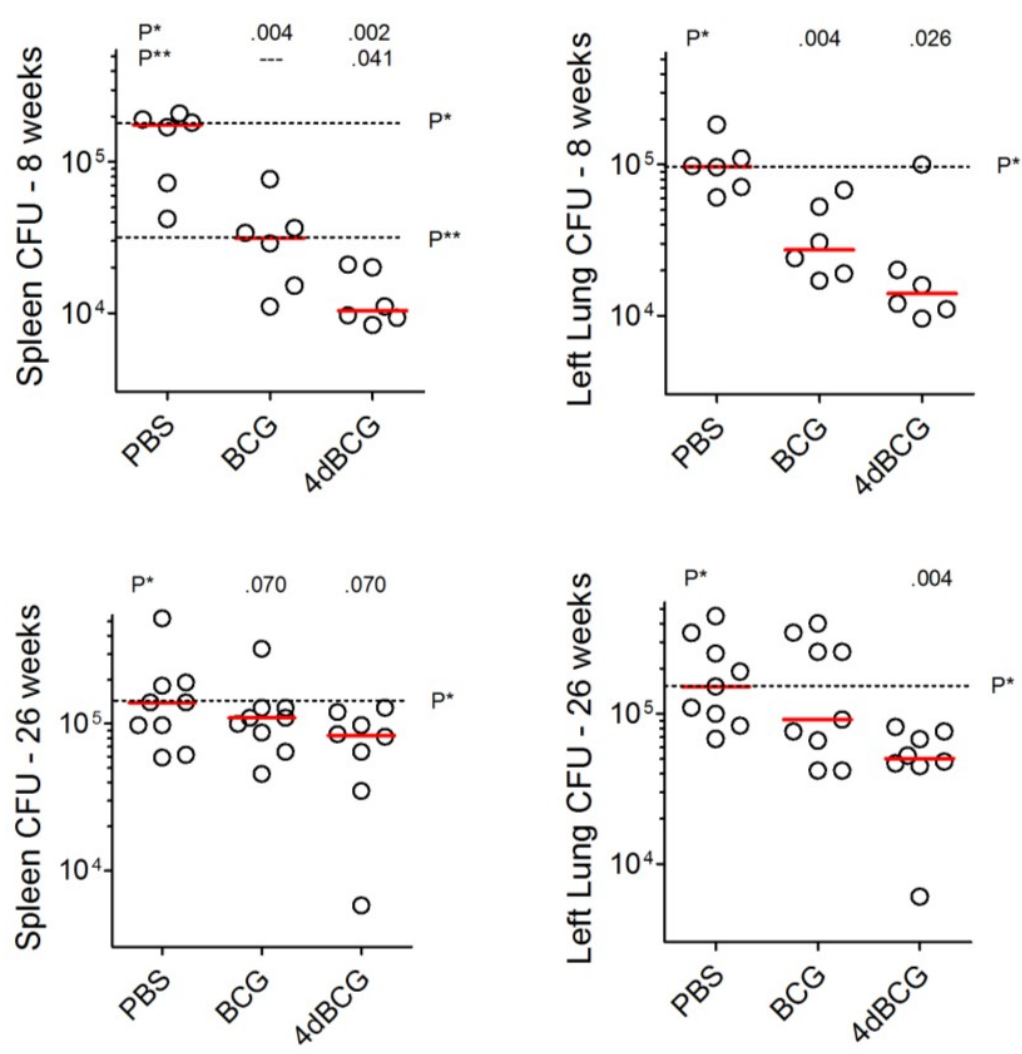
2.4. Vaccination with $4 d B C G$ Alters the Pattern of Lymphohistiocytic Infiltration of Lung Parenchyma at 8 Weeks Post-Challenge

CFU counts are an incomplete measure of vaccine-induced protection against pulmonary $\mathrm{TB}$, and thus we also evaluated the effect of vaccination upon lung pathology. To display these results objectively, we took low power photomicrographs ( $\times 2$ magnification $)$ of H\&E-stained sections of lung tissue covering about $70 \%$ of the lung tissue on each slide for three mice per vaccination arm (Figure 4). We marked the parts of the low-power photomicrographs that were enlarged further to display representative histopathologic features. Thus the reader can visualize the representative features in the context of the whole lung cross-sections. As shown in Figure 4, regions of relatively unconsolidated lung parenchyma were observed in all three vaccination arms. Mice vaccinated with PBS exhibited relatively more inflammation and consolidation of lung tissue at 8 weeks post-aerosol challenge with M. tuberculosis compared to mice vaccinated with BCG and mice vaccinated with 4dBCG.

Figure 4. Low-power photomicrographs of sections of lung tissue. (Upper left panel, labeled "Slides") Photographs of the microscope slides containing H\&E-stained lung sections are shown from right lungs of three mice from each of the PBS, BCG, and 4dBCG vaccination arms at 8 weeks post-aerosol challenge with $100 \mathrm{cfu}$ of $M$. tuberculosis strain Erdman S-1. Three rectangles are labeled a, b, and c and cover approximately $70-80 \%$ of the lung tissue on each slide. (Panels labeled "PBS", "BCG", and "4dBCG") Three low-power photomicrographs of the lung tissue were taken through the $2 \times$ microscope objective and correspond to the three rectangles in each lung labeled a, b, and c in the "slides" panel. Within these photomicrographs, the black rectangles highlight lymphohistiocytic nodules in relatively consolidated regions of lung tissue, which are enlarged further and displayed in Figure 5. The white rectangles in the $4 \mathrm{dBCG}$ group of mice outline lung tissue containing bronchus-associated lymphoid tissue (BALT) and are displayed in Figure 7.

\section{Slides}

1

PBS

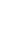

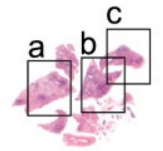

2

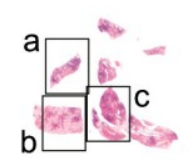

3

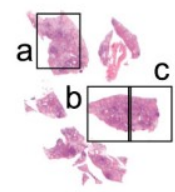

BCG
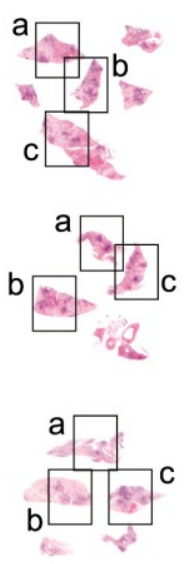

4dBCG
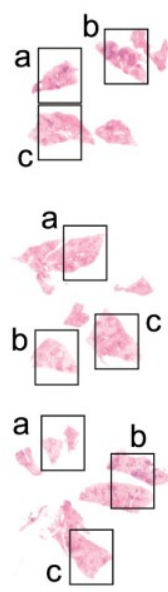

PBS

(x2)

1

3

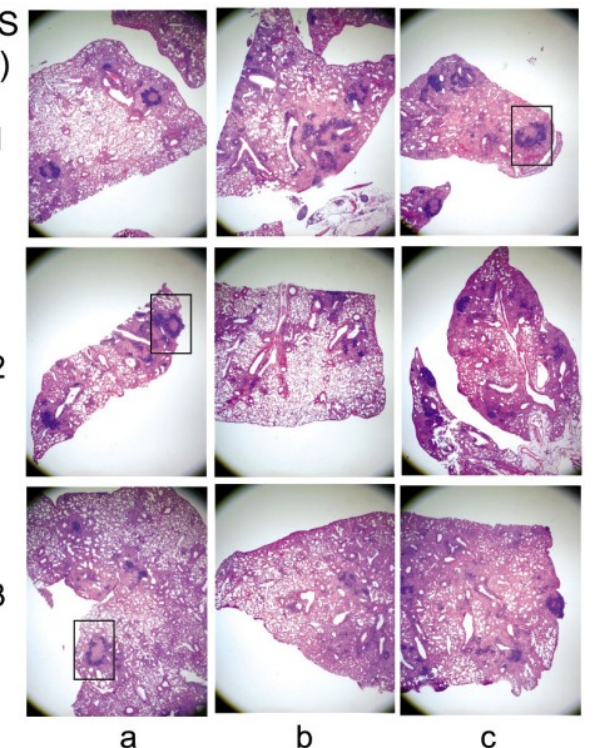


Figure 4. Cont.
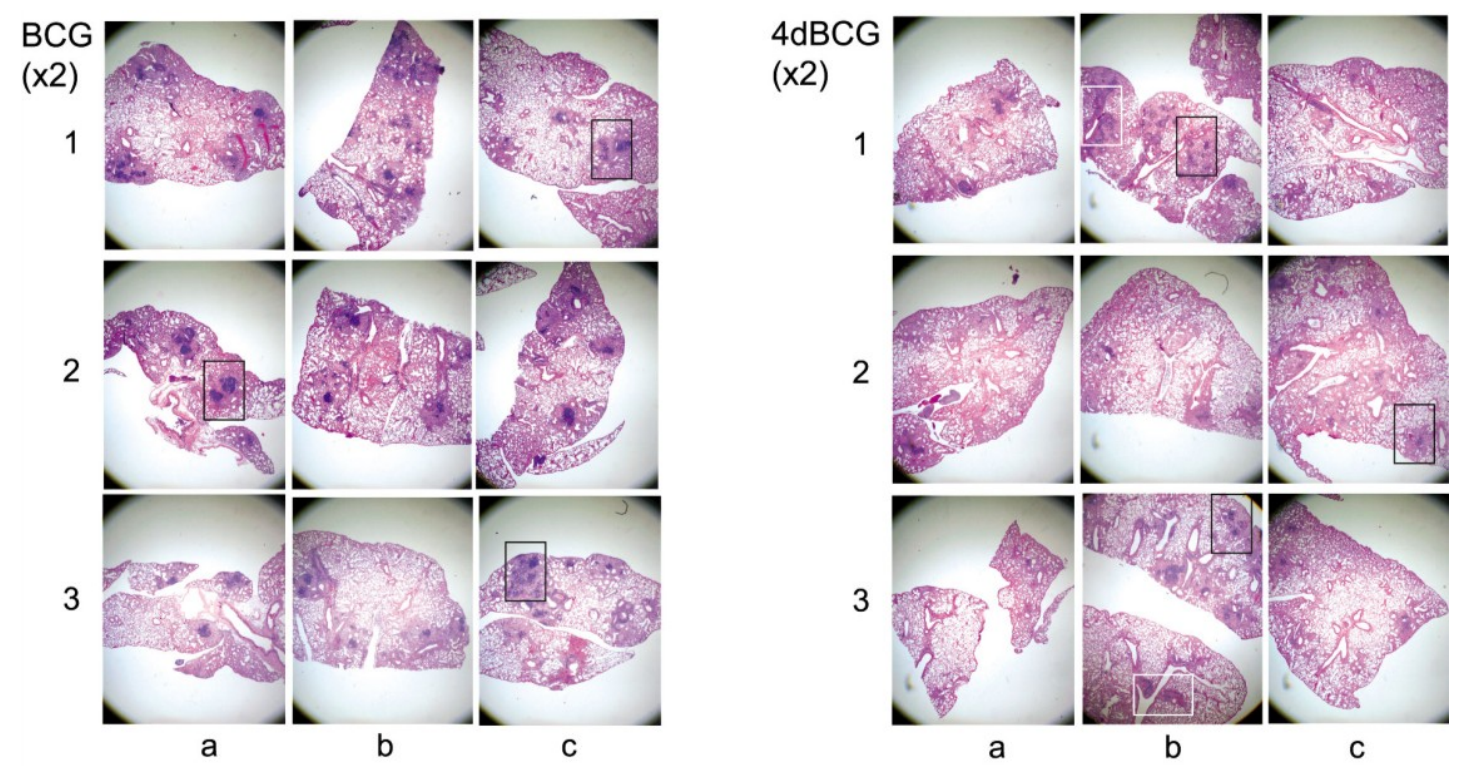

The most apparent difference in lung histopathology between vaccination arms involved the lymphohistiocytic nodules, which stain dark blue due to the density of nuclei and scant cytoplasm within lymphocytes (Figures 4 and 5). They were most numerous and well-developed in the PBS vaccination arm, often exhibiting a circumferential or near-circumferential ring of lymphocytes around epithelioid cells that had replaced normal alveolar architecture (Figures 5 and 6). Also staining dark blue was bronchus-associated lymphoid tissue (BALT). BALT typically can be distinguished from lymphohistiocytic nodules within the lung parenchyma by its association with bronchovascular structures (Figures 5 and 7) and was observed in all 3 vaccination arms.

Compared to $\mathrm{BCG}$, the lungs of mice vaccinated with $4 \mathrm{dBCG}$ exhibited smaller collections of lymphocytes within the lung parenchyma with less disruption of alveolar architecture as demonstrated by better preservation of the alveolar walls and fewer epithelioid cells (Figures 5 and 6). There was also more generalized eosinophilic staining of the lungs of mice vaccinated with $4 \mathrm{dBCG}$ (Figrue 4), due in part to extravasated RBCs and edema fluid.

\subsection{Vaccination with 4dBCG Reduces Lung Cfu Counts at 26 Weeks Post-Challenge}

Due to weight loss in PBS-vaccinated mice the experiment was limited to 26 weeks post-challenge. At this time the mice vaccinated with BCG or $4 \mathrm{dBCG}$ exhibited spleen cfu titers that were not significantly lower than cfu titers in the PBS vaccination arm (Figure 3). Lung histopathology revealed extensive granulomatous inflammation in all 3 groups of mice (not shown). Lung cfu titers in the $4 \mathrm{dBCG}$ vaccination arm were significantly lower than titers in the PBS vaccination arm (median values of $5.0 \times 10^{4} \mathrm{cfu}$ and $1.5 \times 10^{5} \mathrm{cfu}$, respectively, $\left.p=0.004\right)$. 
Figure 5. Lymphohistiocytic nodules in the lung parenchyma. Mid-power $(\times 10$ microscope objective) photomicrographs of regions of lung consolidation within the tissue sections in Figure 4 are displayed at a greater magnification. Most of the areas that stain dark blue in the PBS and BCG groups represent dense collections of lymphocytes within the lung parenchyma that are accompanied by lymphohistiocytic infiltration and consolidation of the alveolar spaces. Examples of these regions are indicated with arrows (black arrowheads) and the white rectangles outline regions of lung tissue that are enlarged further in Figure 6. Lymphoid aggregates were also observed in the lung parenchyma in the $4 \mathrm{dBCG}$ group of mice however they were typically smaller with less dense alveolar infiltrate compared to the PBS and BCG groups. The arrows with white arrowheads indicate BALT, which is distinguished from lymphohistiocytic nodules in the lung parenchyma by their association with blood vessels and bronchi.
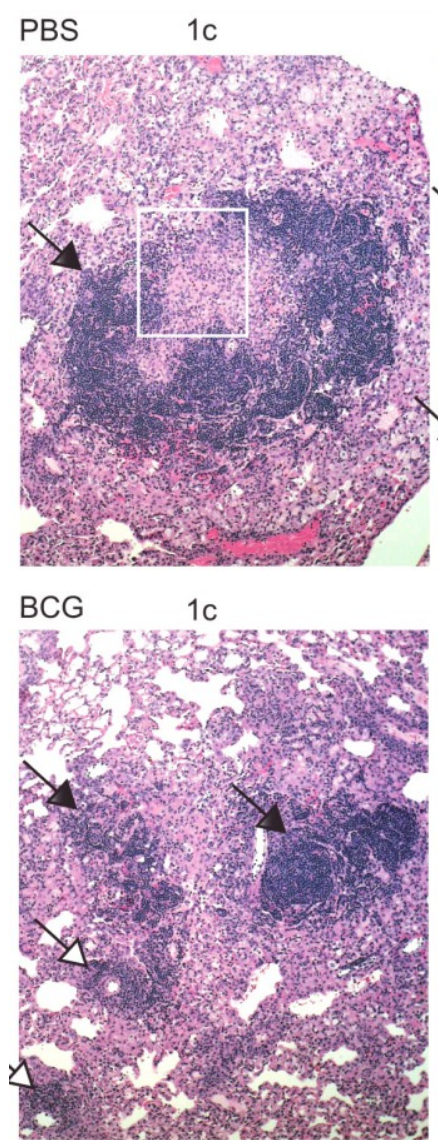

$4 \mathrm{dBCG} \quad 1 \mathrm{~b}$

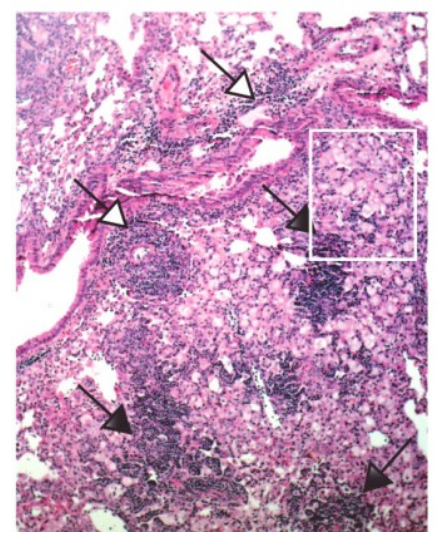

$2 a$

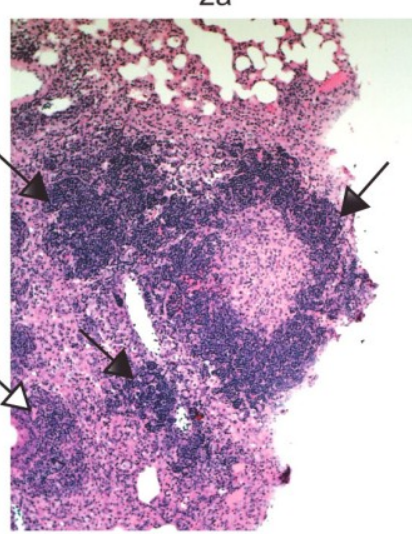

$2 \mathrm{a}$

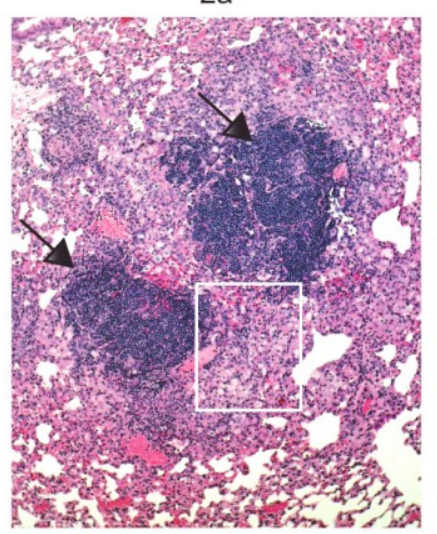

2c

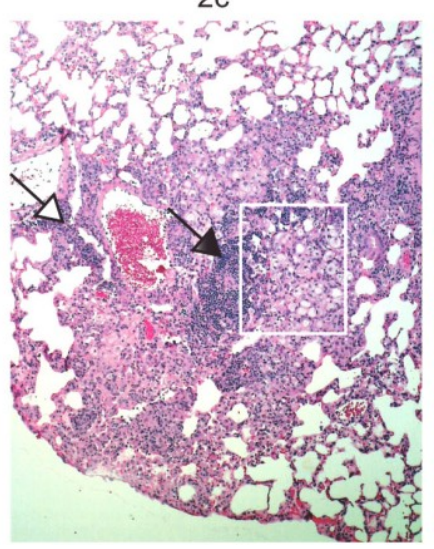

$3 a$

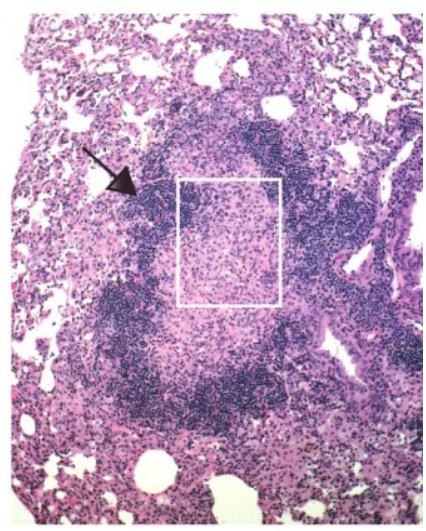

$3 c$

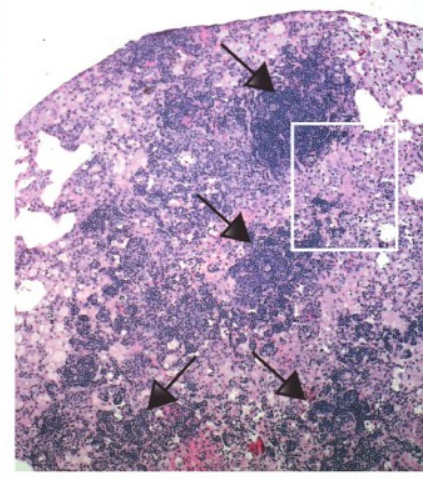

$3 b$

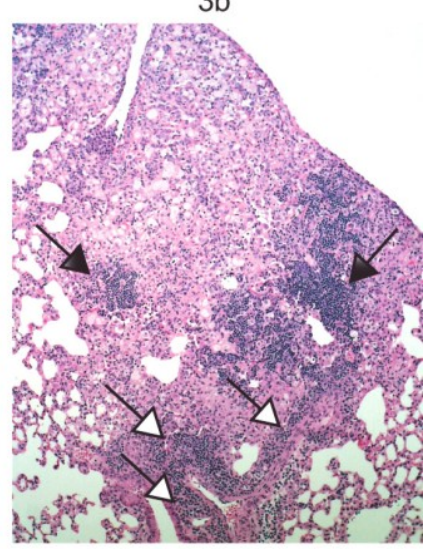


Figure 6. High-power views of lymphohistiocytic nodules. Consolidated lung tissue with many epithelioid cells containing pale oval nuclei and eosinophilic cytoplasm are observed in the PBS-vaccinated mice and to a lesser degree in the BCG-vaccinated mice. The alveolar spaces adjacent to the smaller lymphoid nodules in the 4dBCG-vaccinated mice are edematous, contain relatively fewer epithelioid cells, and exhibit greater preservation of alveolar wall architecture than in the PBS- and BCG-vaccinated mice.
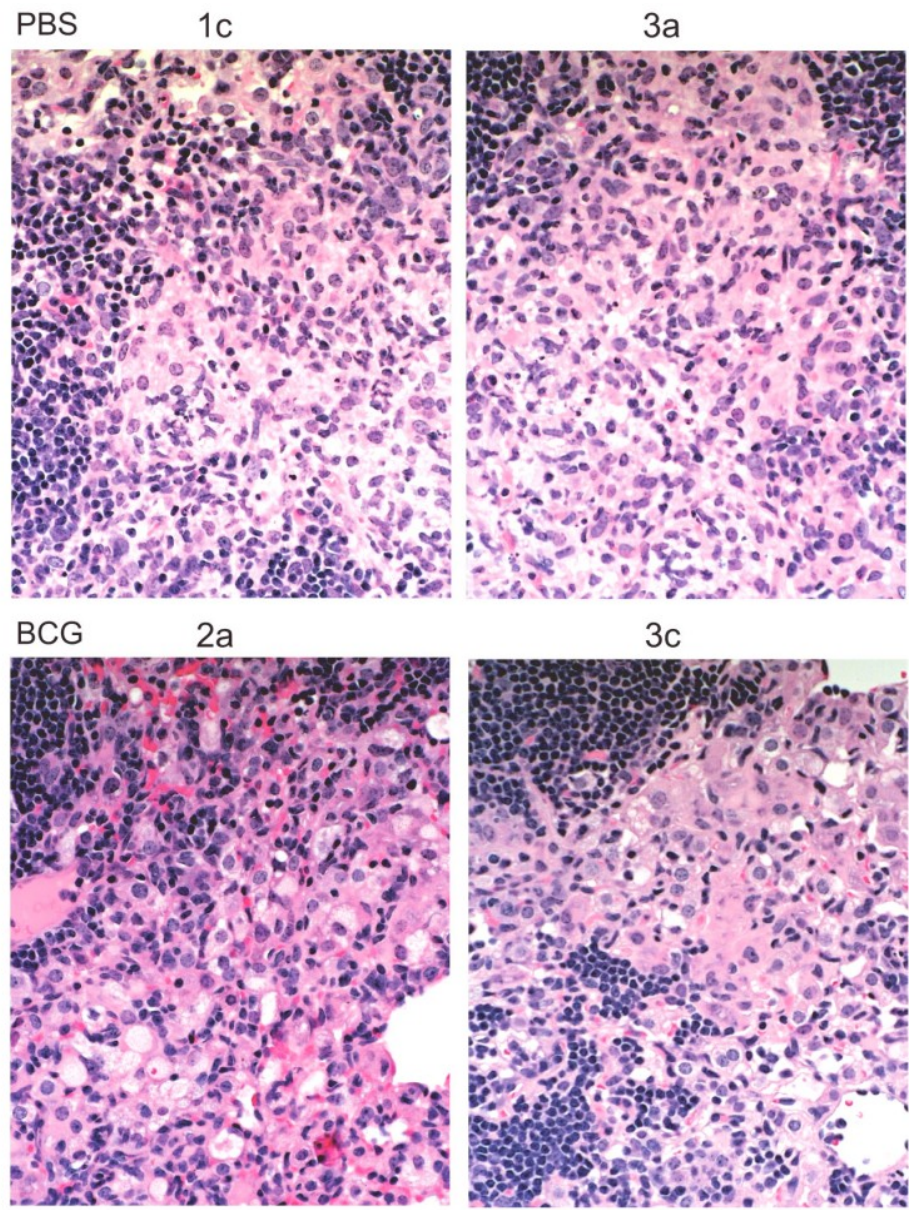

$4 \mathrm{dBCG}$

$1 \mathrm{~b}$

2c
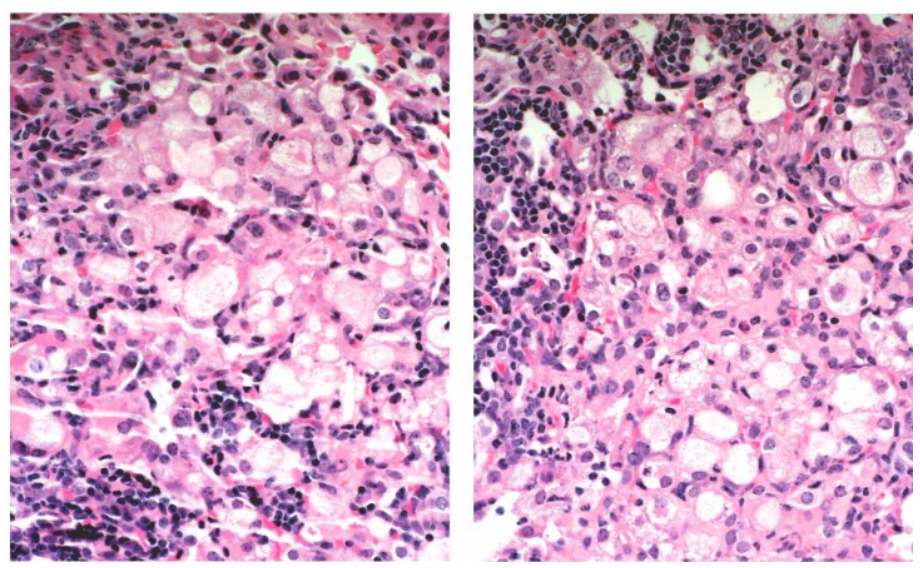
Figure 7. Bronchus-associated lymphoid tissue (BALT). The panels display $\times 10$ enlargements of the lung sections from mice vaccinated with $4 \mathrm{dBCG}$ as represented by the white rectangles in Figure 4. BALT was prominent along the central bronchovascular structures in all three groups of mice (see Figure 5) and its association with blood vessels and bronchi distinguishes BALT from collections of lymphocytes in the lung parenchyma.
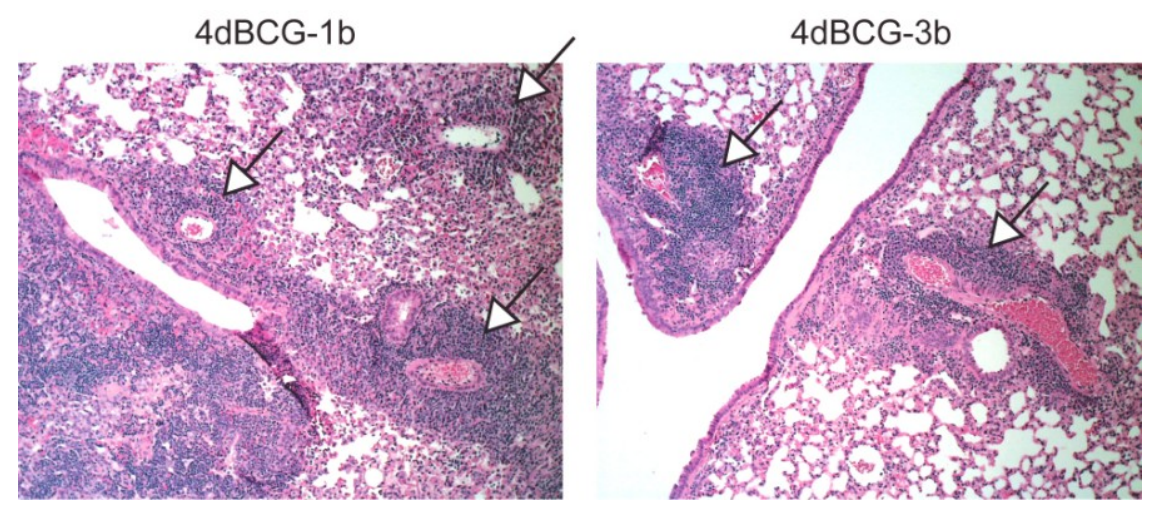

\subsection{Advantages and Limitations of This Vaccine Strategy and Its Implications for Human Vaccination}

The results of these experiments support efforts to improve the safety and effectiveness of BCG by targeting microbial factors that suppress host immune responses. We previously have reported that $3 \mathrm{dBCG}$, with 3 attenuating modifications, surpasses the parent BCG Tice vaccine in the induction of primary and secondary immune responses and in the clearance of challenge bacilli in a memory-immune model of subcutaneous vaccination followed by intravenous challenge [12]. Other groups of TB vaccine investigators have reported that the immunogenicity and protective efficacy of BCG can be improved by disrupting sapM and zmpl, microbial genes that encode, respectively, an acid phosphatase and zinc metalloprotease implicated in inhibition of phagosome maturation [42-45]. Collectively, there is now substantial evidence that the immunogenicity of BCG can be improved by targeting immune suppressive microbial factors.

The present investigation further explores this strategy for improving BCG and demonstrates that despite diminished persistence in vivo 4dBCG surpasses the parent BCG Tice vaccine in protecting mice against the dissemination of an aerosolized challenge of $M$. tuberculosis from the lung to the spleen. Vaccination with $4 \mathrm{dBCG}$ also altered lung histopathology to result in fewer and less well-developed lymphohistiocytic nodules within the lung parenchyma at 8 weeks post-challenge. At 26 weeks post-challenge mice vaccinated with $4 \mathrm{dBCG}$ had significantly fewer bacilli in the lungs than control mice. The biological mechanisms that underlie the improved protection observed with $4 \mathrm{dBCG}$ have not been fully explored, however oxidants and glutamate are signaling molecules that activate antigen-presenting cells and $\mathrm{T}$ cells [46-50], promote apoptosis and apoptosis-associated cross presentation of bacterial antigens to induce CD8 $+\mathrm{T}$ cell responses [49,51,52], and influence the balance between Th1 and Th17 responses [53,54]. Thus our modifications to BCG may have enhanced protection by unmasking protective host responses that are suppressed by the parent BCG vaccine.

There are several issues worthy of discussion regarding how these results fit into the TB vaccine literature and their implications for human vaccination. First, it is noteworthy that we used a relatively high dose of $4 \mathrm{dBCG}$ and $\mathrm{BCG}, 2 \times 10^{7} \mathrm{cfu}$, which is greater than the $3.7 \times 10^{4} \mathrm{cfu}$ to $3 \times 10^{6} \mathrm{cfu}$ 
typically used for human vaccination [1]. The ability of some BCG substrains to induce protection with doses as low as $10^{1} \mathrm{cfu}$ has been interpreted by some experts as indicative of vaccine potency [32,55-58] such that vaccines with this capability including Pasteur 1173P2 and Danish 1331 are called "strong" strains whereas those without this capability including Tokyo 172 are called "weak" [59,60]. The biological reason for this difference has traditionally been attributed to differences in the ability of the live vaccine to multiply within the host and the BCG vaccines exhibiting the smallest allergenic, i.e., DTH-inducing, doses also exhibit greater lethality in golden hamsters and cause more adverse effects in man [32,59-62]. As 4dBCG was less capable of persisting in the spleens of mice than the parent BCG Tice vaccine it behaves more like the "weak" BCG daughter strains and accordingly we used a relatively high dose for vaccination. It is possible that a smaller dose of $4 \mathrm{dBCG}$ would not confer as much protection. Despite this uncertainty, we have concerns about the ability of some BCG substrains to induce protection with a low dose; in the context of a modern understanding of host-pathogen interactions this capability indicates that the vaccine strain is able to suppress the host responses needed to eradicate live mycobacteria, which is not a good property for a vaccine.

A second issue is that the protection induced by vaccination with $4 \mathrm{dBCG}$ waned over time. This was not unexpected as the waning of protection is characteristic of vaccination with BCG in small animal models [63]. Recent results involving C57Bl/6 mice and the same lot of the Erdman challenge strain used in our study found that vaccination with BCG Pasteur conferred protection at 4 and 10 weeks post-aerosol challenge, but not at 20 weeks [64]. Thus, although the magnitude of protection induced by $\mathrm{BCG}$ and $4 \mathrm{dBCG}$ in our study declined over time, these results are consistent with prior experience and our observation of continued, albeit reduced, protection at 26 weeks post-challenge in the $4 \mathrm{dBCG}$ vaccination arm exceeds the duration of protection usually observed in this model. Extrapolation from such results to expectations regarding vaccine effectiveness in man is difficult however it is important to remember that whereas $\mathrm{C} 57 \mathrm{Bl} / 6$ mice invariably develop progressive infection that damages the lung [65] 90\% of human hosts control aerogenic infection with $M$. tuberculosis for the duration of their lives. Accordingly, the real goal of vaccination against $M$. tuberculosis is to induce in the $10 \%$ of persons who are relatively susceptible to the development of active TB the type(s) of immune responses that protect $90 \%$ of us. As the immune system of man exhibits important differences from the immune system of mice [66] and is superior in restricting the growth of mycobacteria in vivo [21,67], it is possible that the modest enhancements in protection we observed in mice may correlate with enhanced protection against pulmonary TB in man.

A third issue is that although vaccination altered lung histopathology and 4dBCG induced greater changes than BCG in comparison with control mice, the implications of these findings are unclear. In $\mathrm{C} 57 \mathrm{~B} 1 / 6$ mice, the dense aggregates of lymphocytes in the lung parenchyma are comprised primary of B cells and surrounded by macrophages [68,69]. Defects in CXCL13 and IL-23 signaling have been associated with fewer and smaller B cell follicles in mice along with impaired containment of M. tuberculosis [70], suggesting that the follicles contribute to protection. Yet most human hosts are able to resolve the granulomatous lesions of primary infection with M. tuberculosis, which are often marked by foci of calcification within the lung parenchyma and hilar lymph nodes to form a Ghon complex [71]. Thus the presence of fewer and smaller lymphohistiocytic nodules in 4dBCG-vaccinated mice could represent a defect in the formation of these structures or instead reflect the unmasking of host responses involved in resolving granulomatous inflammation. There is growing appreciation in 
man that immune surveillance by $\mathrm{CD} 8+\mathrm{T}$ cells helps to prevent latent $\mathrm{TB}$ infection from developing into active pulmonary TB [72-74]. Although such responses are not expressed well enough in mice to prevent eventual lung destruction, they may tip the balance towards the resolution of granulomatous inflammation and the containment of infection in human hosts who are intrinsically better than mice at controlling M. tuberculosis.

The fourth issue is a question that is at the heart of any attempt to improve BCG. Is it better to administer a relatively virulent live vaccine that persists in vivo such that immune effector cells are already present when the host subsequently becomes infected with M. tuberculosis or instead is it better to use a less immune suppressive vaccine that induces host immune responses that not only eradicate the vaccine strain but also produce memory immunity that can be recalled years later when the host becomes infected? The current BCG daughter strains provide some insight into this important question. More than 40 years ago, two relatively "strong" BCG daughter strains, Pasteur $1173 \mathrm{P} 2$ and Danish 1331, were selected for evaluation in a large randomized prospective clinical trial of BCG vaccination in India on the basis of their relative ranking in animal models together with concern about the possible over-attenuation of BCG [32,58,60,61,75]. Yet neither vaccine was effective [76]. Although this was the only randomized trial to compare the protective efficacy of different BCG vaccines, it has subsequently been suggested that case-control studies in which a BCG substrain is replaced by another BCG substrain during the study interval can provide insight into their relative effectiveness. This type of analysis demonstrates that the relatively "weak" BCG Tokyo 172 vaccine confers $50-60 \%$ protection against pulmonary TB and is more effective in man than "strong" Pasteur 1173P2 and Danish 1331 vaccines [77-79]. A recent cohort study in Kazakhstan reported similar findings with BCG Tokyo 172 exhibiting greater protection effectiveness than BCG Russia and a Serbian formulation of BCG Pasteur 1173P2 [80]. Correlating these results in man with the results from an earlier report of the persistence of the same BCG substrains in mice [37] answers the question posed at the beginning of this paragraph. In effect, there is an inverse correlation between the protection effectiveness of a BCG substrain in man and its persistence in the spleens of mice (Figure 8). This important observation further justifies efforts to improve BCG by reducing its capacity for immune suppression. It also invites a reevaluation of the historical criteria used to evaluate the potency of BCG daughter strains and to designate them as "strong" or "weak".

Finally, the inverse correlation noted above raises a fifth issue about our study. In essence, Figure 8 suggests that the BCG substrain used for genetic modifications will be an extremely important variable in vaccine effectiveness. We used BCG Tice, a vaccine strain that historically was considered to be of relatively low virulence [36] but was reformulated with a subculture of BCG obtained from the Institut Pasteur in 1951 and subsequently has exhibited in vivo persistence in small animal models similar to that observed with BCG Pasteur 1173P2 [81-83]. Our modifications to BCG Tice reduced in vivo persistence and per the inverse correlation shown in Figure 8 we expect that $4 \mathrm{dBCG}$ will exhibit enhanced protection effectiveness in man. However, we can only speculate as to the magnitude of the improvement and whether $4 \mathrm{dBCG}$ will be more or less protective in man than BCG Tokyo 172. Although our modifications were a step in the right direction, ideally the starting strain used for genetic modifications should be a BCG substrain with high protection effectiveness in man. Some progress towards this goal has been achieved; in 2009, while the Aeras Global TB Vaccine Foundation held an exclusive license for Vanderbilt University's pro-apoptotic bacterial vaccine technology [84], 
and based in part on our concern about the potential triplication of $\operatorname{sig} H$ and other virulence genes in recombinant vaccines derived from BCG Danish 1331 [85] that Aeras was using for vaccine construction [15], we encouraged Aeras to instead introduce the genetic modifications described in the current study and our earlier work [12] into BCG Tokyo 172. Two of these modifications, inactivation of SecA2 and the chromosomal insertion of a dominant-negative $\Delta \mathrm{H} 28 \Delta \mathrm{H} 76$ sodA allele, were introduced into a GMP (good manufacturing practices) stock of BCG Tokyo 172 (Final Progress Report from Aeras to Vanderbilt University, May 2011). Although Aeras decided not to develop this vaccine candidate or modify it further, based on the findings of this study and the experience with "weak" and "strong" BCG vaccines in man (Figure 8), we expect that it would likely exhibit enhanced protection against pulmonary $\mathrm{TB}$.

Figure 8. Inverse correlation between protection effectiveness in man and spleen titer in mice of three BCG daughter strains. The protection effectiveness values were taken from a cohort study in Kazakhstan [80] and involved BCG Russia (Microgen), Pasteur 1173P2 (Serbian "Torlak" vaccine), and BCG Tokyo 172 (Japan BCG Laboratory). The $\log 10$ spleen titer values were taken from a comparison of 5 BCG strains in Balb/C mice [37] and represent the values at 12 weeks after intravenous inoculation of mice with $10^{6} \mathrm{cfu}$ of the vaccine strain.

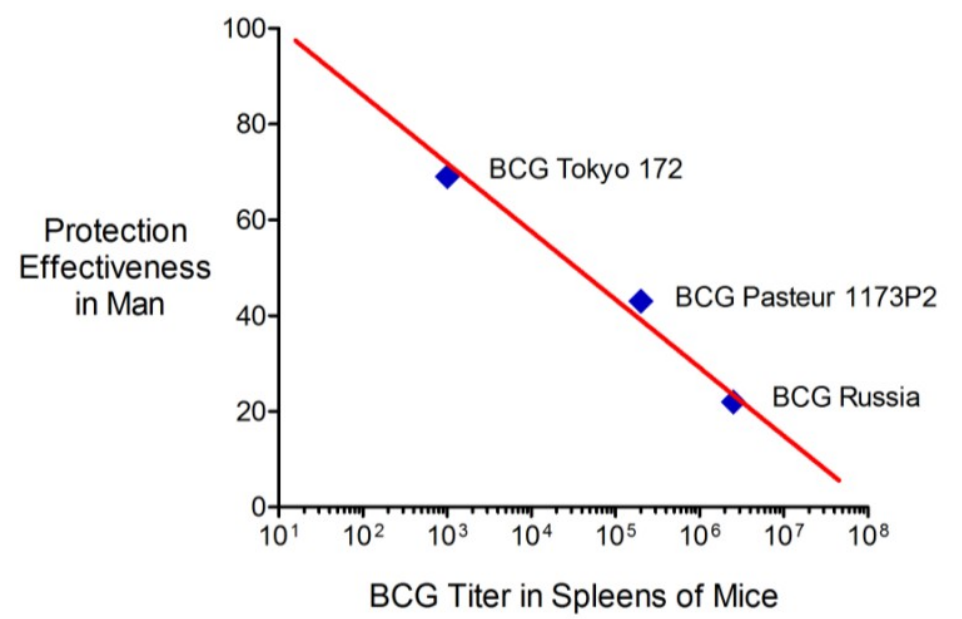

In summary, we have described an alternative strategy for modifying BCG based on reducing the activity and secretion of multiple immune suppressive microbial factors. Our vaccine strategy challenges the traditional prioritization of BCG vaccines based on their performance in small animal models. Indeed, we consider the virulence attributes of the "strong" BCG vaccines that have previously been regarded as indicators of potency to instead reflect their immune suppressive capacity. In the context of the repeated failure of "strong" BCG vaccines to exhibit protection against pulmonary $\mathrm{TB}$ in man and their associated adverse effects, it is time to consider a different direction in TB vaccine development based on the construction and evaluation of modified BCG vaccines with diminished immune suppressive capacity. 


\section{Experimental}

\subsection{Bacterial Isolates, Plasmids, Antibiotics, and Media}

Genetic tools and bacterial isolates are listed in Table 1. E. coli strains were grown in LB media. Genetic modifications were introduced into BCG Tice. To prepare vaccine inocula BCG Tice and $4 \mathrm{dBCG}$ were grown in Middlebrook $7 \mathrm{H} 9$ media with $10 \%$ oleic acid-dextrose-catalase (OADC) enrichment supplemented with $0.2 \%$ glycerol, and $0.05 \%$ Tween 80 . Kanamycin $(50 \mu \mathrm{g} / \mathrm{mL}$ or $25 \mu \mathrm{g} / \mathrm{mL})$, apramycin $(50 \mu \mathrm{g} / \mathrm{mL})$, and hygromycin B $(100 \mu \mathrm{g} / \mathrm{mL}$ or $50 \mu \mathrm{g} / \mathrm{mL})$ were used to select colonies after genetic manipulations in E. coli or BCG, respectively. Erdman S-1 (lot K01) was provided by the Center for Biologics Evaluation and Research, Food and Drug Administration (FDA), USA in accordance with a collaborative agreement between the FDA and the World Health Organization. This challenge strain is a standardized preparation made available to TB vaccine investigators to help reduce variability between laboratories and in two recent studies that compared several M. tuberculosis challenge strains, Erdman S-1 demonstrated relatively high capacity for disseminating to the spleen after aerosol challenge $[61,86]$.

Table 1. Tools for genetic manipulations and bacterial strains.

\begin{tabular}{|c|c|c|}
\hline Name & Description & Reference or source \\
\hline \multicolumn{3}{|c|}{ Plasmids } \\
\hline pCR2.1-TOPO & Plasmid for cloning PCR products & $\begin{array}{l}\text { Invitrogen Corp., Carlsbad, } \\
\text { California }\end{array}$ \\
\hline pBC SK+ & E. coli phagemid vector & Stratagene, La Jolla, CA \\
\hline pHV203 & $\begin{array}{l}\text { E. coli-mycobacterial shuttle plasmid with } \\
\text { kanamycin resistance gene }\end{array}$ & {$[16]$} \\
\hline pHV203-dnglnA1- $\Delta \mathrm{D} 54 \Delta \mathrm{E} 335$ & $\begin{array}{l}\text { pHV203 with } \triangle \mathrm{D} 54 \Delta \mathrm{E} 335 \text { dn mutant } g \ln A 1 \\
\text { gene with its own promoter }\end{array}$ & This study \\
\hline \multicolumn{3}{|c|}{ Strains } \\
\hline Erdman S-1 & $\begin{array}{l}\text { M. tuberculosis WHO Standard lot } 1 \text { (Mtb S-1) } \\
\text { prepared from virulent Erdman lot K01 from the } \\
\text { Trudeau Institute and filled by Mycos Research, } \\
\text { Loveland, CO }\end{array}$ & $\begin{array}{l}\text { Amy Yang, FDA, Bethesda, } \\
\text { MD [64] }\end{array}$ \\
\hline TOP 10 & $\begin{array}{l}\text { Host strain for cloning PCR products, used in } \\
\text { combination with pCR2.1-TOPO }\end{array}$ & $\begin{array}{l}\text { Invitrogen Corp., Carlsbad, } \\
\text { California }\end{array}$ \\
\hline $\mathrm{DH} 5 \alpha$ & $\begin{array}{l}\text { E. coli host strain for genetic manipulation, } \\
\text { construction of mutant enzyme expression } \\
\text { vectors }\end{array}$ & $\begin{array}{l}\text { Life Technologies, } \\
\text { Gaithersburg, MD [87] }\end{array}$ \\
\hline BCG Tice & Bacillus Calmette-Guérin, substrain Tice & $\begin{array}{l}\text { Organon Teknika Corp., } \\
\text { Durham, NC }[82,83]\end{array}$ \\
\hline \multicolumn{3}{|c|}{ 3rd generation modified BCG vaccine (three modifications) } \\
\hline $3 \mathrm{dBCG}$ & $\begin{array}{l}\text { BCG Tice with inactivated } \operatorname{sig} H \text { and } \sec A 2 \\
\text { containing the chromosomal integration vector } \\
\text { pMP399-dnsodA- } \Delta \mathrm{H} 28 \Delta \mathrm{H} 76\end{array}$ & {$[12]$} \\
\hline \multicolumn{3}{|c|}{ 4th generation modified BCG vaccine (four modifications) } \\
\hline $4 \mathrm{dBCG}$ & $\begin{array}{l}\text { BCG Tice with inactivated } \operatorname{sig} H \text { and } \sec A 2 \\
\text { containing pMP399-dnsodA- } \Delta \mathrm{H} 28 \Delta \mathrm{H} 76 \text { and } \\
\text { pHV203-dnglnA1- } \triangle \mathrm{D} 54 \Delta \mathrm{E} 335\end{array}$ & This study \\
\hline
\end{tabular}




\subsection{Molecular Genetic Manipulations}

Plasmid and chromosomal integration vectors were electroporated as previously described $[12,88]$. After electroporation, Middlebrook 7H9 media was added to the samples, which were incubated in 5\% $\mathrm{CO}_{2}$ at $37{ }^{\circ} \mathrm{C}$ for $24 \mathrm{~h}$ before the suspension was plated on Middlebrook $7 \mathrm{H} 11$ agar containing antibiotics as needed. Successful transformation was confirmed by PCR of DNA unique to the vector.

To construct dominant-negative (dn) enzyme monomers, glnAl was PCR-amplified from DNA of M. tuberculosis strain H37RV, ligated into pCR2.1-TOPO, and propagated in E. coli TOP 10. Site-directed mutagenesis was performed using primer overlap extension methods [89]. Codon deletion was verified by DNA sequencing and the sequence data was deposited in GenBank, Accession No. HM217184.

\subsection{Expression of Mutant Enzyme Alleles in BCG and Assays of Enzyme Activity}

The mutant allele encoding $\Delta \mathrm{D} 50 \Delta \mathrm{E} 327$ GlnA1 (numbering per homologous enzyme in Salmonella typhimurium [30] but actually representing $\Delta \mathrm{D} 54 \Delta \mathrm{E} 335$ deletions in M. tuberculosis GlnA1) was ligated into the shuttle plasmid pHV203 and electroporated into 3dBCG to yield 4dBCG. Immunoblotting was used to compare enzyme quantity. Bacterial lysates were prepared from $25 \mathrm{~mL}$ of $10^{8} \mathrm{cfu} / \mathrm{mL}$ of each strain grown for $48 \mathrm{~h}$ in Middlebrook $7 \mathrm{H} 9$ media with $10 \%$ oleic acid-dextrose-catalase (OADC) enrichment supplemented with $0.2 \%$ glycerol and $0.05 \%$ Tween 80 . Lysates were adjusted to a standard A280 value, applied to a SDS-12\% PAGE gel for separation of proteins by electrophoresis and transferred to nitrocellulose membranes and hybridized with a 1:20 dilution of the anti-GlnA1 antibody IT-58 was obtained from Colorado State University as part of NIH, NIAID Contract HHSN26620040091C, “Tuberculosis Vaccine Testing and Research Materials.” To measure glutamine synthetase activity we monitored $\gamma$-glutamylhydroxamate formation spectrophotometrically at $540 \mathrm{~nm}$ by the $\gamma$-glutamyl transfer reaction [90]. As a factor in the cell lysate partially inhibited the assay, we first treated the lysate with $50 \%$ ammonium sulfate and then dialyzed the soluble portion with assay buffer, $0.04 \mathrm{M}$ potassium phosphate, $\mathrm{pH} 7.0$, and concentrated to $1 \mathrm{~mL}$ before performing the assay. Hydroxylamine, glutamine, and gamma-glutamylhydroxamate were purchased from Sigma.

\subsection{Animal Procedures}

Experiments involving the monitoring of the vaccine strains in the organs of mice were approved by the Vanderbilt Institutional Animal Care and Use Committee (Protocol No. M/06/069). Experiments involving vaccination-challenge were approved by the Syracuse VAMC Subcommittee on Animal Studies (ACORP Protocol No. 005). Female C57BL/6 mice aged 5-6 weeks were purchased from Jackson Laboratories (Bar Harbor, ME, USA). Methods for preparing inocula of the vaccines and challenge strain are described above. Bacterial suspensions were adjusted to a standard absorbance and diluted to achieve the desired inoculum. In studies to compare the clearance of vaccine strains, mice were inoculated by tail vein or retro-orbital injection.

In the vaccination-challenge experiments mice were vaccinated subcutaneously and rested until challenge by aerosol with $100 \mathrm{cfu}$ of Erdman S-1. For aerosol infection with Erdman S-1, the organism, supplied frozen, was removed from the freezer, thawed, sonicated and diluted to a final 
concentration of $1 \times 10^{6} \mathrm{cfu} / \mathrm{mL}$ and ten $\mathrm{mL}$ of the inoculum was aerosolized to deliver $\sim 100 \mathrm{cfu} /$ mouse. Some mice were euthanized and their lungs harvested $24 \mathrm{~h}$ post-challenge to verify the challenge dose.

To enumerate bacteria in the organs of mice, mice were euthanized with $\mathrm{CO}_{2}$ inhalation and the spleens and left lungs were removed aseptically and placed in a sealed grinding assembly (IdeaWorks! Laboratory Products, Syracuse, NY, USA) attached to a Glas-Col Homogenizer (Terre Haute, IN, USA). Viable bacterial counts were determined by titration on $7 \mathrm{H} 10$ agar plates containing $10 \%$ OADC supplemented with $2 \mu \mathrm{g} / \mathrm{mL}$ of 2-thiophene carbonylhydrazide. During the course of the 26-week vaccination-challenge experiment one mouse in the 4dBCG vaccination arm was euthanized for humane reasons related to problems with excessive grooming.

\subsection{Histopathology}

At the time of harvest, right lungs from each vaccination arm were submersed in formalin. The lungs from each mouse were routinely cut at two levels in antero-posterior sagittal planes. All pieces from a single mouse were embedded flat on the cut surfaces in a single paraffin block. The lungs were cut into 4- $\mu \mathrm{m}$ sections and stained with hematoxylin and eosin (H\&E). Occasionally the sections displayed the whole sagittal plane of the right lung at different levels. To illustrate differences in the magnitude of parenchymal lung involvement and loss of alveolar architecture between different vaccination arms, the slides were laid on white paper and photographed with a digital camera. Then three photomicrographs covering 70 to $80 \%$ of the visible lung on the slide from three mice in each group were taken using a $\times 2$ microscope objective and digital microscope camera (Olympus America, Inc., Melville, NY, USA). Higher-magnification views were taken as needed to display specific features. To prepare the multi-panel figures, we used Adobe ${ }^{\circledR}$ Illustrator (Adobe Systems, Inc., San Jose, CA, USA) to place photographs within each figure. Then the composite figure was modified within Adobe ${ }^{\circledR}$ Photoshop where autolevel, brightness, and contrast adjustments were applied uniformly to the whole figure to optimize the display.

\subsection{Statistical Comparisons}

Statistical analyses were performed using Prism 5.0 software (GraphPad) and only significant $(p<0.05)$ or close to significant $(p<0.1)$ values are indicated. Unless otherwise indicated, calculations were performed using the two-tailed Mann-Whitney test.

\section{Conclusions}

The strategy of preferring BCG daughter strains based on in vivo virulence and persistence has failed. The BCG vaccines designated as "strong" on the basis of historical criteria have problems with inadequate safety in immune suppressed persons, adverse reactions in normal hosts, poor memory T-cell responses, and poor protection against pulmonary TB. In this investigation we demonstrate that by targeting microbial enzymes implicated in immune suppression, the in vivo persistence of BCG is reduced while protection in a vaccine-challenge model is enhanced. We believe that the strategy of improving BCG by reducing its immune suppressive capacity addresses the major limitations of 
current BCG vaccines against TB, modifying BCG in a manner that should make it a safer and more effective vaccine against pulmonary tuberculosis in man. This strategy for improving BCG should also work well in combination with new boosting vaccines against $\mathrm{TB}$, which are more likely to be effective if the initial priming vaccine is highly immunogenic rather than immune suppressive.

\section{Conflict of Interests}

DSK is a named inventor on issued patents for modified BCG vaccines with reduced activity of anti-apoptotic microbial enzymes including mycobacterial antioxidants. The technology has been assigned to Vanderbilt University and the United States Government as represented by the Department of Veterans Affairs. MB is a named inventor on a patent application for SecA2 deletion filed by the University of North Carolina, Albert Einstein College of Medicine, and the Howard Hughes Medical Institute. None of the other authors have a financial interest related to this work.

\section{Acknowledgments}

We thank Gretchen Edwards for assistance with the assays.

\section{References}

1. Fine, P.E.M.; Carneiro, I.A.M.; Milstien, J.B.; Clements, J.D. Issues Relating to the Use of BCG in Immunization Programs, a Discussion Document, Document WHO/V\&B/99.23 ed.; World Health Organization Department of Vaccines and Biologicals: Geneva, Switzerland, 1999.

2. Andersen, P.; Doherty, T.M. The success and failure of BCG-Implications for a novel tuberculosis vaccine. Nat. Rev. Microbiol. 2005, 3, 656-662.

3. Behr, M.A.; Wilson, M.A.; Gill, W.P.; Salamon, H.; Schoolnik, G.K.; Rane, S.; Small, P.M. Comparative genomics of BCG vaccines by whole-genome DNA microarray. Science 1999, 284, 1520-1523.

4. Brosch, R.; Gordon, S.V.; Garnier, T.; Eiglmeier, K.; Frigui, W.; Valenti, P.; Dos, S.S.; Duthoy, S.; Lacroix, C.; Garcia-Pelayo, C.; et al. Genome plasticity of BCG and impact on vaccine efficacy. Proc. Natl. Acad. Sci. USA 2007, 104, 5596-5601.

5. Trunz, B.B.; Fine, P.; Dye, C. Effect of BCG vaccination on childhood tuberculous meningitis and miliary tuberculosis worldwide: A meta-analysis and assessment of cost-effectiveness. Lancet 2006, 367, 1173-1180.

6. Bonifachich, E.; Chort, M.; Astigarraga, A.; Diaz, N.; Brunet, B.; Pezzotto, S.M.; Bottasso, O. Protective effect of Bacillus Calmette-Guérin (BCG) vaccination in children with extra-pulmonary tuberculosis, but not the pulmonary disease. A case-control study in Rosario, Argentina. Vaccine 2006, 24, 2894-2899.

7. Bjartveit, K. Olaf Scheel and Johannes Heimbeck: Their contribution to understanding the pathogenesis and prevention of tuberculosis. Int. J. Tuberc. Lung Dis. 2003, 7, 306-311.

8. Aronson, J.D.; Aronson, C.F.; Taylor, H.C. A twenty-year appraisal of BCG vaccination in the control of tuberculosis. Arch. Intern. Med. 1958, 101, 881-893. 
9. Aronson, N.E.; Santosham, M.; Comstock, G.W.; Howard, R.S.; Moulton, L.H.; Rhoades, E.R.; Harrison, L.H. Long-term efficacy of BCG vaccine in American Indians and Alaska Natives: A 60-year follow-up study. JAMA 2004, 291, 2086-2091.

10. Behr, M.A.; Small, P.M. Has BCG attenuated to impotence? Nature 1997, 389, 133-134.

11. Kernodle, D.S. Decrease in the effectiveness of Bacille Calmette-Guérin vaccine against pulmonary tuberculosis: A consequence of increased immune suppression by microbial antioxidants, not overattenuation. Clin. Infect. Dis. 2010, 51, 177-184.

12. Sadagopal, S.; Braunstein, M.; Hager, C.C.; Wei, J.; Daniel, A.K.; Bochan, M.R.; Crozier, I.; Smith, N.E.; Gates, H.O.; Barnett, L.; et al. Reducing the activity and secretion of microbial antioxidants enhances the immunogenicity of BCG. PLoS One 2009, 4, e5531.

13. Horwitz, M.A.; Harth, G.; Dillon, B.J.; Maslesa-Galic', S. Recombinant bacillus Calmette-Guérin (BCG) vaccines expressing the Mycobacterium tuberculosis 30-kDa major secretory protein induce greater protective immunity against tuberculosis than conventional BCG vaccines in a highly susceptible animal model. Proc. Natl. Acad. Sci. USA 2000, 97, 13853-13858.

14. Grode, L.; Seiler, P.; Baumann, S.; Hess, J.; Brinkmann, V.; Eddine, A.N.; Mann, P.; Goosmann, C.; Bandermann, S.; Smith, D.; et al. Increased vaccine efficacy against tuberculosis of recombinant Mycobacterium bovis bacille Calmette-Guérin mutants that secrete listeriolysin. J. Clin. Invest. 2005, 115, 2472-2479.

15. Sun, R.; Skeiky, Y.A.; Izzo, A.; Dheenadhayalan, V.; Imam, Z.; Penn, E.; Stagliano, K.; Haddock, S.; Mueller, S.; Fulkerson, J.; et al. Novel recombinant BCG expressing perfringolysin $\mathrm{O}$ and the over-expression of key immunodominant antigens; pre-clinical characterization, safety and protection against challenge with Mycobacterium tuberculosis. Vaccine 2009, 27, 4412-4423.

16. Edwards, K.M.; Cynamon, M.H.; Voladri, R.K.; Hager, C.C.; DeStefano, M.S.; Tham, K.T.; Lakey, D.L.; Bochan, M.R.; Kernodle, D.S. Iron-cofactored superoxide dismutase inhibits host responses to Mycobacterium tuberculosis. Am. J. Respir. Crit. Care Med. 2001, 164, 2213-2219.

17. Braunstein, M.; Espinosa, B.J.; Chan, J.; Belisle, J.T.; Jacobs, W.R., Jr. SecA2 functions in the secretion of superoxide dismutase A and in the virulence of Mycobacterium tuberculosis. Mol. Microbiol. 2003, 48, 453-464.

18. Hinchey, J.; Lee, S.; Jeon, B.Y.; Venkataswamy, M.M.; Chen, B.; Chan, J.; Braunstein, M.; Orme, I.M.; Derrick, S.C.; Morris, S.L.; et al. Enhanced priming of adaptive immunity by a proapoptotic mutant of Mycobacterium tuberculosis. J. Clin. Investig. 2007, 117, 2279-2288.

19. Jain, R.; Dey, B.; Khera, A.; Srivastav, P.; Gupta, U.D.; Katoch, V.M.; Ramanathan, V.D.; Tyagi, A.K. Over-expression of superoxide dismutase obliterates the protective effect of BCG against tuberculosis by modulating innate and adaptive immune responses. Vaccine 2011, 29, 8118-8125.

20. Kaushal, D.; Schroeder, B.G.; Tyagi, S.; Yoshimatsu, T.; Scott, C.; Ko, C.; Carpenter, L.; Mehrotra, J.; Manabe, Y.C.; Fleischmann, R.D.; et al. Reduced immunopathology and mortality despite tissue persistence in a Mycobacterium tuberculosis mutant lacking alternative $\sigma$ factor, SigH. Proc. Natl. Acad. Sci. USA 2002, 99, 8330-8335. 
21. Mehra, S.; Golden, N.A.; Stuckey, K.; Didier, P.J.; Doyle, L.A.; Russell-Lodrigue, K.E.; Sugimoto, C.; Hasegawa, A.; Sivasubramani, S.K.; Roy, C.J.; et al. The Mycobacterium tuberculosis stress response factor $\mathrm{SigH}$ is required for bacterial burden as well as immunopathology in primate lungs. J. Infect. Dis. 2012, 205, 1203-1213.

22. Kernodle, D.S. SigH, antioxidants, and the pathogenesis of pulmonary tuberculosis. J. Infect. Dis. 2012, 205, 1186-1188.

23. Raynaud, C.; Etienne, G.; Peyron, P.; Laneelle, M.A.; Daffe, M. Extracellular enzyme activities potentially involved in the pathogenicity of Mycobacterium tuberculosis. Microbiology 1998, 144, 577-587.

24. Miller, B.H.; Shinnick, T.M. Evaluation of Mycobacterium tuberculosis genes involved in resistance to killing by human macrophages. Infect. Immun. 2000, 68, 387-390.

25. Tullius, M.V.; Harth, G.; Horwitz, M.A. Glutamine synthetase GlnA1 is essential for growth of Mycobacterium tuberculosis in human THP-1 macrophages and guinea pigs. Infect. Immun. 2003, 71, 3927-3936.

26. Manganelli, R.; Voskuil, M.I.; Schoolnik, G.K.; Dubnau, E.; Gomez, M.; Smith, I. Role of the extracytoplasmic-function $\sigma$ factor $\sigma^{\mathrm{H}}$ in Mycobacterium tuberculosis global gene expression. Mol. Microbiol. 2002, 45, 365-374.

27. Raman, S.; Song, T.; Puyang, X.; Bardarov, S.; Jacobs, W.R., Jr.; Husson, R.N. The alternative sigma factor SigH regulates major components of oxidative and heat stress responses in Mycobacterium tuberculosis. J. Bacteriol. 2001, 183, 6119-6125.

28. Harth, G.; Maslesa-Galic, S.; Tullius, M.V.; Horwitz, M.A. All four Mycobacterium tuberculosis $\operatorname{gln} A$ genes encode glutamine synthetase activities but only GlnA1 is abundantly expressed and essential for bacterial homeostasis. Mol. Microbiol. 2005, 58, 1157-1172.

29. Dong, Y.; Demaria, S.; Sun, X.; Santori, F.R.; Jesdale, B.M.; de Groot, A.S.; Rom, W.N.; Bushkin, Y. HLA-A2-restricted CD8+-cytotoxic-T-cell responses to novel epitopes in Mycobacterium tuberculosis superoxide dismutase, alanine dehydrogenase, and glutamine synthetase. Infect. Immun. 2004, 72, 2412-2415.

30. Gill, H.S.; Pfluegl, G.M.; Eisenberg, D. Multicopy crystallographic refinement of a relaxed glutamine synthetase from Mycobacterium tuberculosis highlights flexible loops in the enzymatic mechanism and its regulation. Biochemistry 2002, 41, 9863-9872.

31. Milstien, J.B.; Gibson, J.J. Quality control of BCG vaccine by WHO: A review of factors that may influence vaccine effectiveness and safety. Bull. World Health Organ. 1990, 68, 93-108.

32. Ladefoged, A.; Bunch-Christensen, K.; Guld, J. Tuberculin sensitivity in guinea-pigs after vaccination with varying doses of BCG of 12 different strains. Bull. World Health Organ. 1976, 53, 435-443.

33. Kupferschmidt, K. Infectious disease. Taking a new shot at a TB vaccine. Science 2011, 334, 1488-1490.

34. Ottenhoff, T.H.; Kaufmann, S.H. Vaccines against tuberculosis: Where are we and where do we need to go? PLoS Pathog. 2012, 8, e1002607.

35. Dubos, R.J.; Pierce, C.H. Differential characteristics in vitro and in vivo of several substrains of BCG. IV. Immunizing effectiveness. Am. Rev. Tuberc. 1956, 74, 699-717. 
36. Dubos, R.J.; Pierce, C.H.; Schaefer, W.B. Differential characteristics in vitro and in vivo of several substrains of BCG. III. Multiplication and survival in vivo. Am. Rev. Tuberc. 1956, 74, 683-698.

37. Lagranderie, M.R.; Balazuc, A.M.; Deriaud, E.; Leclerc, C.D.; Gheorghiu, M. Comparison of immune responses of mice immunized with five different Mycobacterium bovis BCG vaccine strains. Infect. Immun. 1996, 64, 1-9.

38. Freudenstein, H.; Pranter, W.; Schweinsberg, H. Assessment of several BCG vaccines in different animal test systems (additional studies to an IABS collaborative assay). J. Biol. Stand. 1979, 7, 203-212.

39. Smith, D.; Harding, G.; Chan, J.; Edwards, M.; Hank, J.; Muller, D.; Sobhi, F. Potency of 10 BCG vaccines as evaluated by their influence on the bacillemic phase of experimental airborne tuberculosis in guinea-pigs. J. Biol. Stand. 1979, 7, 179-197.

40. Hank, J.A.; Chan, J.K.; Edwards, M.L.; Muller, D.; Smith, D.W. Influence of the virulence of Mycobacterium tuberculosis on protection induced by bacille Calmette-Guérin in guinea pigs. J. Infect. Dis. 1981, 143, 734-738.

41. Sekhuis, V.M.; Freudenstein, H.; Sirks, J.L. Report on results of a collaborative assay of BCG vaccines organized by the International Associaton of Biological Standardization. J. Biol. Stand. 1977, 5, 85-109.

42. Festjens, N.; Bogaert, P.; Batni, A.; Houthuys, E.; Plets, E.; Vanderschaeghe, D.; Laukens, B.; Asselbergh, B.; Parthoens, E.; de Rycke, R.; et al. Disruption of the SapM locus in Mycobacterium bovis BCG improves its protective efficacy as a vaccine against $M$. tuberculosis. EMBO Mol. Med. 2011, 3, 222-234.

43. Saleh, M.T.; Belisle, J.T. Secretion of an acid phosphatase (SapM) by Mycobacterium tuberculosis that is similar to eukaryotic acid phosphatases. J. Bacteriol. 2000, 182, 6850-6853.

44. Vergne, I.; Chua, J.; Lee, H.H.; Lucas, M.; Belisle, J.; Deretic, V. Mechanism of phagolysosome biogenesis block by viable Mycobacterium tuberculosis. Proc. Natl. Acad. Sci. USA 2005, 102, 4033-4038.

45. Johansen, P.; Fettelschoss, A.; Amstutz, B.; Selchow, P.; Waeckerle-Men, Y.; Keller, P.; Deretic, V.; Held, L.; Kundig, T.M.; Bottger, E.C.; et al. Relief from Zmp1-mediated arrest of phagosome maturation is associated with facilitated presentation and enhanced immunogenicity of mycobacterial antigens. Clin. Vaccine Immunol. 2011, 18, 907-913.

46. Rutault, K.; Alderman, C.; Chain, B.M.; Katz, D.R. Reactive oxygen species activate human peripheral blood dendritic cells. Free Radic. Biol. Med. 1999, 26, 232-238.

47. Van der Veen, R.C.; Dietlin, T.A.; Karapetian, A.; Holland, S.M.; Hofman, F.M. Extra-cellular superoxide promotes $\mathrm{T}$ cell expansion through inactivation of nitric oxide. J. Neuroimmunol. 2004, 153, 183-189.

48. Pacheco, R.; Oliva, H.; Martinez-Navio, J.M.; Climent, N.; Ciruela, F.; Gatell, J.M.; Gallart, T.; Mallol, J.; Lluis, C.; Franco, R. Glutamate released by dendritic cells as a novel modulator of $\mathrm{T}$ cell activation. J. Immunol. 2006, 177, 6695-6704.

49. Gras, G.; Porcheray, F.; Samah, B.; Leone, C. The glutamate-glutamine cycle as an inducible, protective face of macrophage activation. J. Leukoc. Biol. 2006, 80, 1067-1075. 
50. Xue, H.; Field, C.J. New role of glutamate as an immunoregulator via glutamate receptors and transporters. Front. Biosci. (Schol. Ed.) 2011, 3, 1007-1020.

51. Jabs, T. Reactive oxygen intermediates as mediators of programmed cell death in plants and animals. Biochem. Pharmacol. 1999, 57, 231-245.

52. Winau, F.; Kaufmann, S.H.; Schaible, U.E. Apoptosis paves the detour path for CD8 T cell activation against intracellular bacteria. Cell. Microbiol. 2004, 6, 599-607.

53. Romani, L.; Fallarino, F.; de Luca, A.; Montagnoli, C.; D’Angelo, C.; Zelante, T.; Vacca, C.; Bistoni, F.; Fioretti, M.C.; Grohmann, U.; et al. Defective tryptophan catabolism underlies inflammation in mouse chronic granulomatous disease. Nature 2008, 451, 211-215.

54. Tse, H.M.; Thayer, T.C.; Steele, C.; Cuda, C.M.; Morel, L.; Piganelli, J.D.; Mathews, C.E. NADPH oxidase deficiency regulates Th lineage commitment and modulates autoimmunity. J. Immunol. 2010, 185, 5247-5258.

55. Jespersen, A. Use of red mice (Clethrionomys g. glareolus Schreb.) for estimation of the ability of vaccines to immunize against tuberculosis. Acta Pathol. Microbiol. Scand. 1954, 34, 157-160.

56. Jespersen, A. Studies on tuberculin sensitivity and immunity in guinea-pigs induced by vaccination with varying doses of BCG vaccine. Acta Pathol. Microbiol. Scand. 1956, 38, 203-210.

57. Jespersen, A.; Bentzon, M.W.; Magnusson, M. Development of tuberculin sensitivity and acquired resistance to tuberculosis in guinea pigs vaccinated with a small dose of BCG vaccine. Acta Pathol. Microbiol. Scand. 1962, 54, 291-304.

58. Ladefoged, A.; Bunch-Christensen, K.; Guld, J. The protective effect in bank voles of some strains of BCG. Bull. World Health Organ. 1970, 43, 71-90.

59. World Health Organization Department of Vaccines and Biologicals. Adverse Events Following BCG Vaccination, Chapter 2 in Clements, C. J., Supplementary Information on Vaccine Safety, Document WHO/V\&B/00.36 ed.; Geneva, Switzerland, 2000.

60. Gheorghiu, M.; Carnus, H.; Lagrange, P.; Chambon, L. Potency and suppurative adenitis in BCG vaccination. Dev. Biol. Stand 1978, 41, 79-84.

61. Bunch-Christensen, K.; Ladefoged, A.; Guld, J. The virulence of some strains of BCG for golden hamsters. Bull. World Health Organ. 1968, 39, 821-828.

62. Bunch-Christensen, K.; Ladefoged, A.; Guld, J. The virulence of some strains of BCG for golden hamsters. Further studies. Bull. World Health Organ. 1970, 43, 65-70.

63. Smith, D.W.; Wiegeshaus, E.; Navalkar, R.; Grover, A.A. Host-parasite relationships in experimental airborne tuberculosis. I. Preliminary studies in BCG-vaccinated and nonvaccinated animals. J. Bacteriol. 1965, 91, 718-724.

64. Jeon, B.Y.; Derrick, S.C.; Lim, J.; Kolibab, K.; Dheenadhayalan, V.; Yang, A.L.; Kreiswirth, B.; Morris, S.L. Mycobacterium bovis BCG immunization induces protective immunity against nine different Mycobacterium tuberculosis strains in mice. Infect. Immun. 2008, 76, 5173-5180.

65. Rhoades, E.R.; Frank, A.A.; Orme, I.M. Progression of chronic pulmonary tuberculosis in mice aerogenically infected with virulent Mycobacterium tuberculosis. Tuber. Lung Dis. 1997, 78, 57-66.

66. Albina, J.E. On the expression of nitric oxide synthase by human macrophages. Why no NO? J. Leukoc. Biol. 1995, 58, 643-649. 
67. Dutta, N.K.; Mehra, S.; Didier, P.J.; Roy, C.J.; Doyle, L.A.; Alvarez, X.; Ratterree, M.; Be, N.A.; Lamichhane, G.; Jain, S.K.; et al. Genetic requirements for the survival of tubercle bacilli in primates. J. Infect. Dis. 2010, 201, 1743-1752.

68. Tsai, M.C.; Chakravarty, S.; Zhu, G.; Xu, J.; Tanaka, K.; Koch, C.; Tufariello, J.; Flynn, J.; Chan, J. Characterization of the tuberculous granuloma in murine and human lungs: Cellular composition and relative tissue oxygen tension. Cell. Microbiol. 2006, 8, 218-232.

69. Gonzalez-Juarrero, M.; Turner, O.C.; Turner, J.; Marietta, P.; Brooks, J.V.; Orme, I.M. Temporal and spatial arrangement of lymphocytes within lung granulomas induced by aerosol infection with Mycobacterium tuberculosis. Infect. Immun. 2001, 69, 1722-1728.

70. Khader, S.A.; Guglani, L.; Rangel-Moreno, J.; Gopal, R.; Junecko, B.A.; Fountain, J.J.; Martino, C.; Pearl, J.E.; Tighe, M.; Lin, Y.Y.; et al. IL-23 is required for long-term control of Mycobacterium tuberculosis and B cell follicle formation in the infected lung. J. Immunol. 2011, 187, 5402-5407.

71. Ober, W.B. Ghon but not forgotten: Anton Ghon and his complex. Pathol. Annu. 1983, 18, $79-85$.

72. Pathan, A.A.; Wilkinson, K.A.; Wilkinson, R.J.; Latif, M.; McShane, H.; Pasvol, G.; Hill, A.V.; Lalvani, A. High frequencies of circulating IFN- $\gamma$-secreting CD8 cytotoxic T cells specific for a novel MHC class I-restricted Mycobacterium tuberculosis epitope in M. tuberculosis-infected subjects without disease. Eur. J. Immunol. 2000, 30, 2713-2721.

73. Tully, G.; Kortsik, C.; Hohn, H.; Zehbe, I.; Hitzler, W.E.; Neukirch, C.; Freitag, K.; Kayser, K.; Maeurer, M.J. Highly focused $\mathrm{T}$ cell responses in latent human pulmonary Mycobacterium tuberculosis infection. J. Immunol. 2005, 174, 2174-2184.

74. Carranza, C.; Juarez, E.; Torres, M.; Ellner, J.J.; Sada, E.; Schwander, S.K. Mycobacterium tuberculosis growth control by lung macrophages and CD8 cells from patient contacts. Am. J. Respir. Crit. Care Med. 2006, 173, 238-245.

75. Irvine, K.N. B.C.G. Vaccination in Theory and Practice; Blackwell Scientific Publications, Ltd.: London and Oxford, UK, 1949.

76. Tuberculosis Prevention Trial. Trial of BCG vaccines in south India for tuberculosis prevention: First report. Bull. World Health Organ. 1979, 57, 819-827.

77. Comstock, G.W. Identification of an effective vaccine against tuberculosis. Am. Rev. Respir. Dis. Epidemiol. Rev. 1988, 138, 479-480.

78. Comstock, G.W. Evaluating vaccination effectiveness and vaccine efficacy by means of case-control studies. Epidemiol. Rev.1994, 16, 77-89.

79. Comstock, G.W. Simple, practical ways to assess the protective efficacy of a new tuberculosis vaccine. Clin. Infect. Dis. 2000, 30, S250-S253.

80. Favorov, M.; Ali, M.; Tursunbayeva, A.; Aitmagambetova, I.; Kilgore, P.; Ismailov, S.; Chorba, T. Comparative tuberculosis (TB) prevention effectiveness in children of Bacillus Calmette-Guérin (BCG) vaccines from different sources, Kazakhstan. PLoS One 2012, 7, e32567.

81. Dubos, R.J.; Pierce, C.H. Differential characteristics in vitro and in vivo of several substrains of BCG. I. Multiplication and survival in vitro. Am. Rev. Tuberc. 1956, 74, 655-666.

82. Oettinger, T.; Jorgensen, M.; Ladefoged, A.; Haslov, K.; Andersen, P. Development of the Mycobacterium bovis BCG vaccine: Review of the historical and biochemical evidence for a genealogical tree. Tuber. Lung Dis. 1999, 79, 243-250.

83. Dubos, R.J.; Pierce, C.H. Tice strain of BCG. Am. Rev. Tuberc. 1957, 75, 692-693. 
84. Kernodle, D.S.; Bochan, M.R. Pro-apoptotic bacterial vaccines to enhance cellular immune responses (United States Patent no. 8,021,671; World Intellectual Property Organization publication No. WO/2002/062298. Available online: http://patentscope.wipo.int/search/en/ WO2002062298/ (accessed on 18 December 2012).

85. Kernodle, D.S. Warning: Differences in the copy number of duplication unit 2 (DU2) within BCG Danish 1331 may influence findings involving genetically modified BCG Danish strains. Vaccine 2012, 30, 6013-6014.

86. Palanisamy, G.S.; Smith, E.E.; Shanley, C.A.; Ordway, D.J.; Orme, I.M.; Basaraba, R.J. Disseminated disease severity as a measure of virulence of Mycobacterium tuberculosis in the guinea pig model. Tuberculosis (Edinb.) 2008, 88, 295-306.

87. Hanahan, D. Studies on transformation of Escherichia coli with plasmids. J. Mol. Biol. 1983, 166, 557-580.

88. Braunstein, M.; Bardarov, S.S.; Jacobs, W.R., Jr. Genetic methods for deciphering virulence determinants of Mycobacterium tuberculosis. Meth. Enzymol. 2002, 358, 67-99.

89. Ho, S.N.; Hunt, H.D.; Horton, R.M.; Pullen, J.K.; Pease, L.R. Site-directed mutagenesis by overlap extension using the polymerase chain reaction. Gene 1989, 77, 51-59.

90. Woolfolk, C.A.; Shapiro, B.; Stadtman, E.R. Regulation of glutamine synthetase. I. Purification and properties of glutamine synthetase from Escherichia coli. Arch. Biochem. Biophys. 1966, 116, 177-192.

(C) 2013 by the authors; licensee MDPI, Basel, Switzerland. This article is an open access article distributed under the terms and conditions of the Creative Commons Attribution license (http://creativecommons.org/licenses/by/3.0/). 